\title{
MARCAS EN LA ANTROPOLOGÍA ARGENTINA: EL ENFOQUE "FENOMENOLOGICO", UNA PERSPEECTIVA TEÓRICO-METODOLÓGICA HEGEMÓNICA EN LA HISTORIA DE LA DISCIPLINA
}

\section{Brands in Argentina's anthropology: the "phenomenological" approach, a theoretical and methodological hegemonic perspective in the history of the discipline}

\section{ALEJANDRO 0. BALAZOTE* Y MÓNICA B. ROTMAN**}

Fecha de recepción: 15 de mayo de 2016- Fecha de aprobación: 29 de junio de 2016

\section{Resumen}

Abordamos en este texto aspectos de la perspectiva teórico-metodológica de Marcelo Bórmida; figura vinculada a las primeras décadas de la antropología en Argentina y que marcara fuertemente la orientación de la misma a nivel disciplinar, con actuación básicamente en contextos de gobiernos de facto. La obra de Marcelo Bórmida es muy amplia y abarca investigaciones sobre temáticas arqueológicas, de antropología física y etnológicas. En este último campo podemos diferenciar los textos que se refieren a aspectos teórico-metodológicos y aquellos que abordan una casuística particular. Esta distinción repara solamente en los objetivos explicitados en cada trabajo, dado que frecuentemente los primeros ejemplifican con las investigaciones realizadas en campo por Bórmida y sus discípulos, así como también, los textos más "etnográficos" son estructurados (y recortados) con el fin de confirmar los supuestos teóricos fundantes de su concepción fenomenológica. La unicidad y homogeneidad de los trabajos etnográficos en la obra de nuestro autor es consistente y puesta en función de consolidar su propuesta teórica. En este artículo analizamos tres tópicos que adquieren centralidad en la obra del autor: el tratamiento de lo económico, su concepción de la historia y el enfoque sobre el relacionamiento entre lo material y lo simbólico.

Palabras clave: Marcelo Bórmida, antropología en Argentina, teoría antropológica

\begin{abstract}
In this text, we analized some of the aspects of the theoretical and methodological perspective of Marcelo Bórmida; as a figure linked to the first decades of Argentina's anthropology marks the orientation of the discipline in contexts of military governments. Marcelo Bórmida's work is large and it goes from archaeological research to physic anthropology and ethnology. In the latter field, we can differentiate the theoretical-methodological texts from the cases. This distinction repairs only on the objectives of each works, because the firsts ones exemplified the research on field conducted by Bórmida in and his disciples, as well as and the most "ethnographic" texts are structured (and cut) to confirm the theoretical assumptions of his phenomenological approach. The uniqueness and homogeneity of this author's ethnographic work is consistent to consolidate his theoretical proposal. In this paper, we analyze three topics that acquire centrality in the author's work: the treatment of economics, his conception of history and focus on the relationship between the material and the symbolic.
\end{abstract}

Keywords: Marcelo Bórmida, anthropology in Argentina, anthropological theory

* Doctor en Antropología. Profesor Facultad de Filosofía y Letras, Universidad de Buenos Aires/ Universidad Nacional de Luján, Buenos Aires, Argentina. Correo-e: abalazote336@gmail.com

** Doctora en Antropología. Profesora Instituto de Ciencias Antropológicas (ICA), Facultad de Filosofía y Letras, Universidad de Buenos Aires, Consejo Nacional de Investigaciones Científicas y Técnicas (CONICET), Buenos Aires, Argentina Correo-e: mobea@fibertel.com.ar 


\section{Introducción ${ }^{1}$}

Cabe comenzar explicando las razones por las cuales en este trabajo nos centramos en un autor, Marcelo Bórmida, cuya relevancia actual en la antropología argentina parece limitarse, en principio, a aquellas líneas de investigación que estudian la historia de la disciplina en nuestro país. Su tratamiento no se debe a la actualidad de sus propuestas, tampoco a su legado teórico ni a la proyección de sus discípulos.

Sin embargo, para entender el desarrollo y algunas de las particularidades de la antropología argentina es fundamental asumir la centralidad de M. Bórmida entre los años 1955 y 1983. No es casual que señalemos fechas que simbolizan, la primera, el inicio de un período dictatorial y la segunda, el comienzo de la actual etapa democrática. Su fallecimiento, acaecido en 1978, no fue obstáculo para que sus discípulos continuaran aplicando sin ningún viso revisionista el programa bormidiano y ejerciendo hegemónicamente el control sobre los recursos destinados a la investigación.

Marcelo Bórmida fue una figura dominante durante las dos primeras décadas de la carrera de Ciencias Antropológicas en la Facultad de Filosofía y Letras (FFyL) de la Universidad de Buenos Aires (UBA). Sus perspectivas teórico-metodológicas y el control sobre los fondos institucionales marcaron el desarrollo de la disciplina hasta el período democrático que se inicia en 1983.

Procedente de Italia, llega a Argentina poco después de la finalización de la Segunda Guerra Mundial. Algunos años después se doctora en la FFyL de la UBA bajo la dirección de José Imbelloni, quien fuera su indiscutido maestro. En 1959 obtiene el cargo de Profesor
Titular Ordinario, cargo máximo de la UBA; desde esta fecha hasta su muerte acaecida en 1978 asumió funciones de máxima responsabilidad, tanto en dicha institución, como en el Consejo Nacional de investigaciones Científicas y Tecnológicas CONICET (principal organismo dedicado a la promoción de la ciencia y la tecnología en el país).

La historia argentina en el período abordado, se caracteriza por la alternancia de gobiernos civiles débiles y dictaduras militares. El ascenso de M. Bórmida acontece durante la denominada Revolución Libertadora, cuando es derrocado el gobierno constitucional de Juan Domingo Perón en 1955, y se instaura un poder de facto, el cual, respecto de las instituciones educativas superiores, procuraba desperonizar el ámbito universitario.

En 1958 se realizan elecciones nacionales siendo proscrito el peronismo; asume la presidencia Arturo Frondizi -el candidato más votado- perteneciente a la UCRI 2 .

El proyecto modernizante, con apoyo de la tendencia liberal-desarrollista, impulsó la creación de carreras nuevas en el área de Humanidades. Hacia fines de la década de 1950 surgen, en la Universidad de Buenos Aires, las de Psicología, Sociología, Ciencias de la Educación y Ciencias Antropológicas. El modelo es claramente instrumental: se trataba de formar científicos capaces de relevar sistemáticamente la realidad y aportar conocimientos para resolver problemas sociales.

A contracorriente de un proyecto desarroIlista modernizador (dominante en el campo intelectual posperonista) que había impulsado la creación de las carreras mencionadas, Ciencias Antropológicas (creada en 1958) adhiere a 
la perspectiva de la Escuela Histórico-Cultural centroeuropea de gran desarrollo durante las primeras décadas del siglo $\mathrm{XX}$, pero anacrónica en la década de los sesenta.

En marzo de 1962, el presidente A. Frondizi fue destituido por las Fuerzas Armadas, sucediéndolo transitoriamente José María Guido quien se encontraba en el primer lugar de la línea sucesoria según la Ley 252 (ley de acefalía) de 1868.

En el contexto político mencionado, y en una carrera de reciente formación, M. Bórmida iniciaba sus actividades en la UBA. En tal período, su producción teórica se focaliza en estudios arqueológicos y sin grandes rupturas continuó la línea iniciada por su maestro Imbelloni. Su programa teórico-metodológico consistió en la aplicación de los preceptos provenientes de la escuela Histórico-cultural. Recién hacia fines de la década de 1960 se producirá su "viraje" a la "fenomenología", con una muy particular apropiación de la misma. Su desinterés por "la problemática social actual" se manifiesta en su nostálgico pesar por la "pérdida progresiva de las culturas primitivas", siendo estas su objeto de estudio, a las cuales hay que "recuperar"; esta cuestión en modo alguno implica un interés por analizar el proceso histórico que explicaba las condiciones de existencia y reproducción de los pueblos originarios.

En 1963, en las elecciones presidenciales convocadas por J.M. Guido (y con la proscripción del peronismo), es elegido el candidato de la Unión Cívica Radical (UCR) Humberto Illia. En 1966 nuevamente un golpe cívico militar derroca al gobierno, asumiendo el poder las fuerzas armadas hasta 1973. En esta ocasión, el régimen de facto intervino las universidades violando la autonomía que habían obtenido después de la reforma universitaria del año 1918. Docentes y estudiantes tomaron las casas de estudio procurando oponerse a tal medida y fueron violentamente reprimidos por fuerzas policiales, hecho que se conoció como "la noche de los bastones largos". Muchos profesores e investigadores renunciaron, otros fueron despedidos. La policía destrozó laboratorios y bibliotecas y "Clementina”, la primera computadora de Latinoamérica fue desmantelada mientras numerosos científicos migraban hacia otros países, principalmente a Chile y Venezuela.

Mientras esto acontecía, en la FFyL de la UBA, Marcelo Bórmida se reunía con un grupo de docentes y estudiantes de Antropología que renunciaban o abandonaban el claustro debido al quiebre del orden constitucional, a la represión ejercida por las fuerzas policiales y a la intervención de la universidad, diciéndoles y señalando amenazadoramente la salida "(...) es muy fácil salir por esa puerta, pero es muy difícil volver a entrar (...)" (comunicación personal).

La figura de M. Bórmida eclipsó durante esos años a otros profesores, y sus propuestas teórico-metodológicas signaron el rumbo de aquellos que estudiaban y se formaban dentro de la institución. La discusión en términos teóricos estaba literalmente clausurada. Los intentos de transitar otras alternativas disciplinares debieron llevarse a cabo fuera de la Universidad de Buenos Aires.

En 1973 se convoca a elecciones, resultando electo J. D. Perón. En el breve interregno democrático de los años 1973 y 1974, M. Bórmida se recluye en el CONICET. Sus concepciones disciplinarias e ideológicas no tenían cabida en el proyecto universitario implementado en 
ese breve período, que se caracterizaba por un fuerte compromiso con los sectores populares.

A mediados de 1974 fallece el presidente Perón y lo sucede la vicepresidenta Isabel Martínez de Perón, y a los pocos meses la Universidad de Buenos Aires es intervenida, asumiendo su conducción sectores de ultraderecha. El regreso de M. Bórmida al ámbito universitario fue inmediato. Rápidamente definió un nuevo Plan de estudios para la carrera de Ciencias Antropológicas que incorporaba plenamente en la estructura curricular su perspectiva disciplinaria.

El trágico golpe cívico militar del 24 de marzo de 1976 dio inició a la última dictadura cívico-militar en Argentina. Esta implementó una metodología represiva, constituyéndose como el más sangriento y autoritario de los regímenes ya mencionados. Sus consecuencias devastadoras, la violencia ejercida sobre la población y su política económica no han sido superadas y saldadas todavía en su totalidad hoy en día. En esos años trágicos en los cuales se contaban entre los "desaparecidos" docentes y estudiantes, Bórmida continuó conduciendo la carrera de Ciencias Antropológicas. Su cruzada contra el "materialismo marxista" iba en línea con la aplicación de la Doctrina de la Seguridad Nacional implementada por el gobierno de facto.

En 1978 M. Bórmida fallece, pero sus seguidores continuaron dirigiendo la carrera en la UBA y hegemonizando la disciplina en el CONICET hasta el inicio del periodo democrático en 1983.

La trascendencia de M. Bórmida no se debe al reconocimiento de sus aportes a la producción de conocimiento, sino más bien a las marcas que dejó en la formación teórico-metodológica de distintas generaciones de antropólogos.

La alta conectividad que hubo entre el desarrollo de las Ciencias Antropológicas y los procesos políticos en Argentina es una característica que tuvo fuertes implicaciones en el desarrollo disciplinar. Las concepciones más elitistas en cuanto a las incumbencias del hacer antropológico y etnocéntricas en relación a lo estrictamente teórico-metodológico, se profundizaron en los períodos más autoritarios de las distintas dictaduras militares que marcaron nuestra historia. El desinterés y la indiferencia mayúsculos hacia desarrollos teóricos acaecidos en otros ámbitos académicos y la negación más absoluta a problematizar los procesos sociales de nuestro país, constituyeron un freno para el diseño de una antropología comprometida capaz de producir un conocimiento crítico.

La apropiación de las versiones más dogmáticas de la escuela Histórico-cultural desarrolladas por Imbelloni y profundizadas con la incorporación de Oswald Menghin a la Universidad de Buenos Aires acaecida hacia fines de la década de 1940, tuvieron su continuidad y perfeccionamiento a partir del afianzamiento de Bórmida en los ámbitos académicos.

Este trabajo, más que incursionar en el campo de la historia y de la teoría de la antropología argentina, se origina en preocupaciones relacionadas con el tratamiento de ciertas temáticas abordadas en la obra de Marcelo Bórmida, las cuales resultan relevantes para el rediseño de una matriz teórica que permita comprender la dinámica de los procesos socioculturales de amplio rango (objetivo de improbable cumplimentación dentro de los parámetros del programa bormidiano). 
La obra del autor es muy amplia y abarca investigaciones sobre temáticas arqueológicas, de antropología física y etnológicas; nos centraremos fundamentalmente sobre estas últimas. Dentro de este campo podemos diferenciar los textos que se refieren a aspectos teórico-metodológicos y aquellos que abordan una casuística particular. Tal distinción repara solamente en los objetivos explicitados en cada trabajo, dado que frecuentemente los primeros ejemplifican con las investigaciones realizadas en campo por Bórmida y sus discípulos, así como también, los textos más etnográficos son estructurados (y recortados) con el fin de confirmar los supuestos teóricos fundantes del Programa fenomenológico bormidiano. La unicidad y homogeneidad de los trabajos etnográficos en la obra de nuestro autor es consistente y se halla en función de consolidar su propuesta teórica. A partir de su estudio, en este artículo analizamos tres tópicos que adquieren centralidad en la obra de Marcelo Bórmida: el tratamiento de lo económico, su particular concepción de la historia y el enfoque sobre el relacionamiento entre lo material y lo simbólico.

\section{El dato, el hecho y la reducción economicista}

Bórmida plantea la interferencia del observador entre el hecho cultural y el dato. Según el autor, dicha interferencia hace que necesariamente el segundo "deje de ser el fiel reflejo del primero" perdiendo así su objetividad. Esta "ingenua" exigencia de objetividad lo lleva a plantear la necesidad de prevenir los riesgos de determinados reduccionismos. Los prejuicios del observador y la proyección de las categorías de la cultura occidental (de la que proviene el etnógrafo) impedirían captar en su totalidad las complejidades del hecho cultural.
La siguiente cita ilustra sobre el posicionamiento de Bórmida, acerca de "la objetividad del etnógrafo" así como también sobre su concepción de "lo económico".

\footnotetext{
“ (...) describiendo la pesca entre los Mataco, el etnógrafo tradicional dará por cumplida su misión cuando haya relatado que esta actividad económica es peculiar del varón según la división sexual del trabajo vigente en este grupo-, que se organiza colectivamente-sobre la base de una determinada organización familiar y tribal-, que se utilizan en ella ciertas técnicas y ciertos elementos ergológicos -el acorralamiento de los peces y la red de tijera- que alterna estacionalmente con otras actividades económicas; podrá además agregar información acerca del aprovisionamiento y la conservación de pescados y de todo aquello que de un modo o de otro, considere vinculado con la actividad pesquera de este grupo chaquense (...) Agotada concienzudamente una descripción sobre la base de estos esquemas, estará muy conforme con su objetividad (...) considerará haber consignado en el dato lo que viera y todo lo que viera con respecto al hecho que le interesa"3 (1976b:14).
}

Metodológicamente el campo de debate se reduce a "la fidelidad de la descripción". La misma parece ser un fin en sí mismo y la discusión pasa porque tan fiel resulta. Desde esta perspectiva, el grado de adecuación de los "datos" a los "hechos" es lo que determina el éxito o fracaso de la investigación. En relación a lo que Bórmida entiende por "lo económico" la inclusión sin más de los aspectos ergológicos y tecnológicos al interior del amplio campo de este concepto da indicios de su clasificación disciplinar. Su materialidad los encuadra dentro del esquema teórico del autor en los bordes de la "ciencia del espíritu" que encarna la etnología.

La inadecuación entre el dato y el hecho es fruto de la proyección de esquemas cognitivos propios del investigador en el análisis cultural. El resultado de esta práctica metodológica es la 
reducción de la diversidad y complejidad cultural a una explicación linealmente monocausal.

Bórmida entiende que el reduccionismo $\mathrm{m}^{4}$ es el resultado de forzar una interpretación racionalista de la cultura, de atribuir un sentido racional a aquello que hay de irracional en la misma. Esta postura lo llevaría a plantear que "(...) detrás del hecho cultural, incomprensible de por sí, habría otro hecho, o conjunto de hechos en los cuales se encuentra su explicación y su sentido, a los cuales se reduce" (Op.cit.: 22) (las negritas nos pertenecen). Se exige al etnógrafo deponer (como si eso fuera posible) todo aquello que esté vinculado a una posición teórica previa (Ídem: 37).

Sobre los reduccionismos "de lo irracional de la cultura", plantea la existencia de un reduccionismo psicologista, de uno sociologista, de uno historicista y finalmente de un reduccionismo economicista 5 .

\footnotetext{
"Hay (...) un reduccionismo economicista que ve la cultura como el epifenómeno o la concreción de las relaciones de carácter económico de sus integrantes o de grupos de éstos, tal como lo hacen ciertas corrientes marxistas y otras que, de un modo u otro, se entroncan con el materialismo histórico" (Ídem:22-23).
}

Es significativa la indiferenciación de la expresión "ciertas corrientes del marxismo". Sin embargo, en un pie de página del mismo trabajo destaca posiciones menos simplistas y críticas al marxismo mecanicista como las realizadas por Godelier $(1967)^{6}$. No obstante, en el texto principal no avanza sobre:

1. Cuáles serían las posibilidades teórico-metodológicas de estas corrientes para comprender la "complejidad del hecho etnográfico".
2. En que coinciden y en qué se diferencian de las versiones más lineales y mecanicistas del materialismo histórico.

3. Si el desarrollo de un programa de investigación por parte de tales líneas teóricas evitaría la reducción economicista, o solo sería una versión más prolija de esta.

No podemos dejar de puntualizar el disímil tratamiento consistente en presentar las versiones mecanicistas y dogmáticas en el cuerpo principal del texto y las concepciones del marxismo estructural en un pie de página.

Bórmida plantea el concepto de "hecho concreto" entendido como aquello que se identifica claramente con la "cultura vivida".

\begin{abstract}
"(...) no serán hechos concretos la "economía", la "sociedad", o la religión", sino la acción de cazar o de cultivar, la familia o la tribu, una ceremonia o una teofanía" (1976b:70) (las comillas nos pertenecen).

"La reducción de la interpretación economicista no significa, desde luego, negar que el hecho cultural tenga un aspecto económico, siempre que entendamos lo económico en su acepción más comprensiva. En esta lo económico es equivalente a lo útil y, desde ya sería absurdo afirmar que se dé un solo hecho humano que no tome en consideración la utilidad de los resultados" (Op.cit.:61-62).
\end{abstract}

"Lo económico" es producto del esquema clasificatorio del etnólogo no un "hecho concreto" y su proyección sobre la cultura vivida da como resultado la reducción economicista.

"En el hecho etnográfico en sí, tal como lo piensan y lo viven concretamente los indígenas, no existen fronteras entre la tecnología, la economía, la sociedad, la magia y el mito (...)" (Ídem: 15).

"(...) será tan económico desbrozar el campo mediante el roce como realizar una ceremonia propiciatoria al 
comienzo del ciclo agrícola. Pero es evidente que, en esta acepción lo económico trasciende la significación empírica corriente y se transforma en un valor universal por lo cual, considerando un hecho cultural en su aspecto universal de utilidad - es decir, en aquello que tiene en común con otro cualquier hecho- no agotamos su complejidad ni captamos su originalidad" (ídem:62).

Lo económico tendría una dimensión universal, pero se hallaría desprovisto de sus acepciones corrientes y estaría vinculado (casi estrictamente) a la "utilidad". Desde una concepción relativista, el autor plantea que cada cultura imprime un sentido particular a lo útil ${ }^{7}$.

Seguidamente: si se rescata exclusivamente el sentido universal de lo útil y a partir de esta proyección lo económico se convierte en un valor universal, se dificulta abordar la originalidad y la complejidad de los hechos culturales. La trascendencia de las significaciones empíricas de lo económico nos impide captar la riqueza del registro etnográfico. "Una manera muy particular y muy frecuente de enfocar racionalísticamente [sic] los hechos culturales es verlos en función de la utilidad que proporcionan, es decir, en su aspecto económico" (Ídem: 58).

Al relacionar lo económico con la "utilidad", Bórmida da pautas sobre su concepción de "lo económico". Las teorías utilitaristas han sido profusamente criticadas tanto desde la Economía (a partir de Veblen (1951) hasta Kahneman $(2008)^{8}$, como desde la Antropología Económica (abarcando a Godelier (1966) hasta autores como Douglas e Isherwood (1990). Limitar lo económico al ámbito de la "utilidad" implica desconocer la amplitud del campo disciplinar, sus potencialidades para el estudio de los procesos socioculturales y en el plano epistemológico confinarlo a las expresiones más ingenuas del empirismo. Por otra parte, reducir los postulados de ambas disciplinas a sus versiones más pobres y lineales, es una práctica argumentativa corriente en nuestro autor ${ }^{9}$ que atenta respecto de la presentación de los problemas en toda su riqueza y complejidad.

Lo reseñado del Programa fenomenológico bormidiano hasta aquí, nos lleva a reflexionar sobre:

1. Cuál es la propuesta teórica y metodológica que nos permita producir un conocimiento validado universalmente, así como también cuáles son las características gnoseológicas de la propuesta bormidiana que solo se permite afirmaciones de tipo particular.

2. Las limitaciones del programa para enunciar formulaciones de tipo general. Paradójicamente, el autor no renuncia a la universalidad de la ciencia etnológica, pero en la práctica cae en un marcado particularismo. La única expresión general de la propuesta fenomenológica consiste en señalar la existencia de una conciencia mítica que estaría presente en todos los ámbitos culturales.

La universalidad se lograría sobre la base de las vivencias particulares a partir de la búsqueda de "estructuras generales de existencia o esencias vivenciales" (1976b:30), siendo la reducción eidética el paso metodológico que permite aprehender el objeto de la ciencia etnológica: la cultura vivida.

3. Cuáles son los límites y posibilidades de una metodología comparativa. Para Bórmida lo económico se convierte en una generalización etnocentrista de la cultura occidental cuya proyección sobre "los pueblos etnográficos" oscurece la aproximación fenoménica a la cultura vivida. De acuerdo 
a esto, la ausencia de caracteres homólogos en las prácticas económicas conceptualizadas desde la cultura occidental con las actividades de producción (caza, pesca, recolección, horticultura, cría de animales, etc.), de distribución (reparto de bienes, mecanismos de ayuda mutua, prácticas reciprocitarias; etc.), y de consumo (formas en que es asignado y utilizado el producto social), impide según Bórmida cualquier comparación.

Este último punto sirve a nuestro autor para invalidar al marxismo y a la sociología positivista como dispositivos teóricos para estudiar "la economía etnográfica".

"Un marxista convencido y militante tendrá una disposición más o menos consciente a delimitar la economía etnográfica sobre la base del concepto que es propia de su ideología y, en consecuencia, a excluir de la actividad económica lo referente a las motivaciones y recursos mítico-religiosos" (Op.cit.:40).

"Un sociólogo positivista verá en los nexos de parentesco un conjunto de relaciones socioeconómicas, basadas en la integración de diferentes status y roles en la división del trabajo, le será entonces difícil admitir que estas relaciones no se agotan en lo socioeconómico sino que incluyen relaciones de otra naturaleza, tales como las mágicas o las míticas en las que frecuentemente se halla el sentido más profundo de las relaciones que le interesan (...)" (Ídem: 40-41).

Para el autor el análisis de las "relaciones económicas" es un reduccionismo que oscurece la riqueza y la complejidad "del fenómeno etnográfico", pero el estudio de las relaciones míticas y las prácticas mágicas, por el contrario, permiten captar los sentidos más profundos de la cultura sin por ello constituir dicha elección ninguna reducción.
Cabe la pregunta: para M. Bórmida existe una lógica interna en las sociedades que pauta las condiciones de surgimiento y evolución de las mismas (obviamente distinta de la concebida por el marxismo u otras corrientes teóricas) o bien plantea su inexistencia. Dicho de otro modo: ¿Contempla jerarquías causales dentro de su programa de investigación? Lo explicitado en sus "textos teóricos" pareciera negar esto último; sin embargo, el tratamiento desarrollado en la casuística otorga clara preponderancia a lo ideacional. El "horizonte mítico" es, según su propuesta, la piedra de toque que permite adentrarse en el corazón de la cultura.

\section{Etnología, historia y sujeto histórico}

Es interesante la valorización positiva realizada por Bórmida en los trabajos anteriores a su formulación fenomenológica, sobre los intentos de la Escuela Histórico-cultural por diacronizar el registro cultural. No obstante, hacia fines de la década de 1950, la influencia de su maestro J. Imbelloni comienza a mermar. La crítica al concepto de ciclo cultural no se limitaba al aspecto teórico. El oceonocentrismo, la falta de interés por el estudio "integral y orgánico de las diferentes culturas elementales" (Bórmida, 1956: 14-15) y el uso y abuso de las cartografías etnológicas, constituyeron las primeras formas argumentativas del cuestionamiento. Sin embargo, la más sustancial de las diferenciaciones consistió en el planteo ecuménico, dado que es recién a este nivel que el ciclo cultural adquiere según Bórmida, consistencia.

"Ciclos culturales concretos y unitarios como los expuestos por la Escuela Histórico cultural clásica no han existido jamás. Un ciclo es tan sólo un sistema de isoidas ${ }^{10}$ que expresa un "tipo de civilización" abstracto, reflejo subjetivo de un conjunto cultural polimorfo" (Op.cit.:19-20). 
Es a partir de esta concepción, que el autor formula los lineamientos de la ciencia etnológica y en particular de sus relaciones con la Historia.

"La independencia del ciclo cultural del tiempo es la que nos permite una total identificación de la Etnología con la Prehistoria en cuanto objeto de sus estudios. La unificación de fondo de las manifestaciones actuales y prehistóricas de los ciclos culturales (...)" (Ídem: 23). "La supertemporalidad del ciclo tiene como condición el hecho de que el sistema de isoidas abarque el tipo de civilización desde sus orígenes; esta condición se da solamente cuando el sistema es ecuménico (...). La investigación del ciclo debe realizarse, entonces, en el mundo entero (...)" (Ídem: 24).

La etnología, por una "lógica" división del trabajo con otras ramas de la historia, se ocuparía principalmente de las "culturas primitivas". La autonomía de la disciplina quedaba pues planteada con anterioridad a su viraje fenomenológico. A su vez, la tensión con la antropología adquiere una dimensión importante en la medida que esta se vincula muy estrechamente, según Bórmida, con las corrientes naturalistas: “(...) La antropología, en estrecha conexión con las corrientes naturalistas de la Filosofía, no cesa de roer el campo propio de la Etnología para intentar, finalmente, fagocitarla y reducirla al rango de una de sus subdivisiones" (1958-1959a:316).

Así, en su trabajo "El estudio de los Barbaros desde la antigüedad hasta mediados del siglo XIX. Bosquejo para una historia del pensamiento etnológico", plantea la historia como resultado del pensamiento "individualizante" [sic] que se opone a las ciencias exactas y naturales caracterizadas por una forma de pensamiento "universalizante" [sic] (Op.cit.:299). En este intento de división del trabajo intelectual, la Etnología debería "ambicionar ser parte esen- cial de un humanismo integral" (1956:28).

Cuando Bórmida adopta una concepción fenomenológica, adentrados los años sesenta, concibe la historia como el estudio de las civilizaciones. Para el autor, la historia es la historia de la razón: "La historia, entonces, que en el sentido tradicional del término se inicia con la aparición de la escritura, correspondería en su esencia al comienzo del abandono de la conciencia mítica (...)" (1969-1970: 24).

El surgimiento de la razón y el "inicio de los tiempos históricos" son parte indisoluble de un devenir que no incluye a todos los pueblos y culturas. Así, los "pueblos etnográficos", como gustaba llamarlos Bórmida, conforman procesos particulares cuya intersección con las "culturas de la razón" cobra forma empírica en los escenarios de contacto, en la estructuración de las relaciones interétnicas, en definitiva, en el "choque cultural". Las características de estos "episodios" están preconfiguradas de antemano y la suerte de los pueblos primitivos también.

\footnotetext{
"Es cosa sabida que el papel de los primitivos en la Historia propiamente dicha es insignificante y pasivo; su choque con la cultura occidental se resuelve en episodios marginales, especie de epifenómenos de la Historia, que pueden tener, como mucho, un interés afectivo, y que terminan siempre en su corrupción y muerte como sociedades autónomas (...)" (Bórmida 1956 citado en Herrán ,1990: 109).
}

Su concepción histórica reinterpreta las versiones filosóficas que oponen el mito a la razón. La conciencia mítica estaría presente en todas las sociedades humanas, pero en las civilizadas se encontraría soterrada y acotada por el predominio del pensamiento racional. 
Por el contrario, en los pueblos primitivos el tiempo de los mitos estructura toda secuencia cronológica. La diacronía se resuelve en la constitución de un primer tiempo indiferenciado, el "tiempo mítico" que se proyecta (y opera) sobre el presente. Herrán (1990) señala la diferenciación que realiza Bórmida entre el "hombre histórico" y el "hombre etnográfico". El primero se caracteriza por tener clara conciencia de la sucesión de acontecimientos, clasificándolos y ordenándolos cronológicamente, por el contrario:

"El hombre etnográfico (...) pasa casi sin transición desde los recuerdos vivos de la tradición familiar a un lapso relativamente cercano, en que hechos humanos y divinos, tradición y mito se confunden en una carencia de perspectiva temporal. De este modo el tiempo de los mitos llaga a los umbrales de su vida de todos los días" (Bórmida 1969-1970:19).

En el "hombre etnográfico" se postulan nexos cronológicos diferentes a los que establece la historiografía occidental. Mito e historia, claramente separados en esta última, se imbrican con contigüidad y sin contradicción en el primero. La propuesta de L. Levy Bruhl, constituye para Bórmida, el sustento teórico de lo señalado precedentemente.

Hasta aquí:

1. El autor concibe sujetos históricos trascendentes que forjan los procesos históricos que definen el devenir de la humanidad y pueblos cuya participación en dichos procesos se resuelve marginalmente.

2. La relevancia del estudio de estos últimos, los pueblos bárbaros, consiste en que en ellos se encontrarían "pistas" del hombre prehistórico, en definitiva, de nuestro pasado. El evolucio- nismo de esta propuesta, es evidente pero nunca aceptado.

3. La estructuración dialéctica entre pensamiento racional y pensamiento mítico no se resuelve en una nueva síntesis, sino que es constitutiva de la esencia humana. La primacía de una de ellas por sobre la otra diferencia el salvajismo (o barbarie como señala Bórmida) de la civilización.

4. El "hombre mítico" para el autor no es solamente una construcción teórica, una forma particular de concebir el espacio y el tiempo, sino que se define por una experiencia existencial, una forma de estar-en-el-mundo.

5. La construcción teórica de M. Bórmida postula un "hombre mítico" pero también señala la existencia de una "conciencia mítica", propiciando la creación de una ciencia específica, diferenciada, dedicada no solo al estudio de las religiones sino también de la fenomenología de las religiones, que permitiría "describir la cultura desde adentro" tal como la vive el "hombre mítico".

Esta vivencia no puede ser estudiada a partir de las clasificaciones occidentales: "Un etnógrafo puede muy fácilmente describir una cultura partiendo de la economía o de la organización social y considerar todos sus demás aspectos en función de estas categorías; de este modo distorsionará irremediablemente todo el conjunto" (Op.cit.:44).

En cambio: "Una etnología fundada en una ciencia de la conciencia mítica intenta, en primer lugar, buscar las estructuras generales y permanentes que dan sentido a los hechos culturales particulares" (Ídem: 48). 
6. La primacía de aspectos emotivos e irracionales en el hombre mítico hace que cualquier intento por reducir su cultura a términos "intelectualistas" [sic], a la categorización occidental, implique un recorte arbitrario (Ídem: 29). Lo económico (así como otras categorías) se diluyen en el corpus (aparentemente) indiferenciado de la cultura.

7. No todas las temáticas merecen el mismo interés para el autor (y también para sus seguidores); el estudio de la religión, de la "potencia" y en particular de los mitos, constituyen nodos centrales en la investigación de los "pueblos etnográficos".

“(...) las estructuras de potencia, es decir las diferentes manifestaciones de sacralidad, pueden referirse a la totalidad de los actos de la vida, aún a las categorías y rasgos culturales que, en una sistematización racional de la cultura, nada tienen que ver directamente con lo sagrado; puede haber una "religiosidad" en la economía, en la vivienda, en la tecnología y en cualquier actividad de la vida que un occidental calificaría como profana" (Ídem: 32).

Asimismo, la preocupación de Bórmida porque el dato reflejara fielmente el hecho, implicó simplificaciones metodológicas que se expresaban en las técnicas de registro; el uso y abuso del grabador, permitirían superar las limitaciones teórico-metodológicas; la utilización de este instrumento minimizaba la "distorsión del etnógrafo". "(...) uno de los rasgos más destacados de las publicaciones de esta escuela [consistió en realizar] largas transcripciones literales de mitos y de otros relatos culturales tal como fueron narrados por los informantes" (Gordillo, 1996:148).

8. La actitud metodológica y la técnica expuesta en el punto anterior, se complementan con la práctica de M. Bórmida y sus seguidores de considerar literalmente las afirmaciones de los informantes (Tiscornia \& Gorlier, 1984). El discurso indígena era incorporado sin ningún tipo de revisión teórico-metodológica ni proceso analítico. Si a un etnógrafo de la talla de Marcel Mauss, Lévi- Strauss le cuestionó haber maorizado el "don" planteando una concepción universal del intercambio desde una explicación particular del mismo, como es el hau, advirtiendo que constituía un caso (frecuente) en que el etnólogo había sido "engañado por el indígena"11, no podemos, (por supuesto que sin establecer la mínima comparación entre uno y otro) obviar la marcación de las limitaciones teóricas de esta práctica bormidiana.

Cabe aquí preguntarse sobre las implicaciones del programa fenomenológico aplicado por Bórmida y sus seguidores a partir de la constante recurrencia a la práctica mencionada. La parábola del etnógrafo engañado por el informante, resulta paradójica en el seno de una escuela que hizo gala de la precisión metodológica, aunque esta se limitaba exclusivamente a la precisión del registro de una narrativa particular.

La relación cognoscitiva entre el "hombre histórico" (el etnógrafo) que registra literalmente la narrativa del "hombre etnográfico" queda pues reducida a una ficción en la cual los datos fidedignos son los hechos relatados por este último.

Como ya señaláramos, Bórmida entiende que hay una "historia grande", la de las civilizaciones, y una "historia pequeña", la que se circunscribe a episodios tangenciales del devenir de la humanidad; y la "transcripción literal" de la misma es la tarea del etnógrafo fenomenológico. 
Las consecuencias teóricas y metodológicas de la postura bormidiana han quedado expresadas, no obstante, debemos reparar también en las implicaciones políticas e ideológicas que devienen de dicho posicionamiento. El auge de estas concepciones se relaciona fuertemente con los períodos más represivos y autoritarios de nuestra historia reciente.

No podemos finalizar este acápite sin dejar de mencionar el permanente diálogo entre la etnología fenomenológica de M. Bórmida y sus seguidores con la historiografía producida en las academias militares. La constitución de un indio sin clase y sin historia, reducido a su condición de productor de mitos, cuya suerte lejos de tener centralidad para la construcción del Estado-nación se resolvía en "episodios tangenciales", constituía la versión etnológica más complaciente con las narrativas militares sobre las campañas que estos emprendieron y que ocasionaron el genocidio de los pueblos originarios de nuestro país. La producción de relatos que exaltaban las acciones militares que llevaban la civilización a tierras irredentas (e improductivas para las consideraciones de un proyecto económico y político que respondía a los intereses de la oligarquía latifundista bonaerense) contaba con la complicidad de una etnología que oscurecía las condiciones de vida de los pueblos originarios; no reparaba en sus prácticas económicas ni en el conflicto que estas planteaban por la apropiación y uso de los recursos y no consideraba la inserción de la fuerza de trabajo indígena en los procesos de valorización de capital en el contexto regional. En definitiva, concebía a los pueblos originarios al margen del Estado que los subordinaba en términos políticos y del mercado que vehiculizaba su explotación.

\section{Lo material y lo simbólico}

Hemos señalado la focalización de los trabajos de M. Bórmida (y también de sus seguidores) en determinadas temáticas, fundamentalmente en la mitología y la religión de los "pueblos etnográficos". La ausencia (relativa) de investigaciones sobre otros tópicos, no impidió al autor realizar apreciaciones sustantivas sobre los riesgos de reducir las explicaciones a ciertas categorías occidentales; tampoco limitó sus pronunciamientos sobre el abordaje de aquello que denominaba "cultura material".

Por otra parte, el tratamiento de "lo material" y "lo simbólico", en particular la posibilidad de establecer "relaciones jerárquicas", delimitar "autonomías relativas de las instancias" y "causalidades estructurales", definir si las vinculaciones entre distintos tipos de fenómenos respondían a un orden fijado en torno a "funciones" o a "estructuras", constituían temáticas ampliamente debatidas por los científicos sociales en las décadas de los sesenta y los setenta. Mientras esto se discutía en ámbitos internacionales, Bórmida escribe un largo trabajo titulado "Érgon y mito" (publicado por partes en la revista Scripta Ethnologica entre los años 1973-1978/79). En él fija su posición y plasma su programa de investigación, y elípticamente procura refutar las propuestas teóricas que planteaban cualquier intento por establecer relacionamientos causales entre un "orden material y uno simbólico".

Pensar lo material y lo simbólico desde una concepción no relacional es un error atribuible no exclusivamente a las versiones más mecanicistas del marxismo. Los ejes del debate no necesariamente se encuadran en esta construcción, en la medida que, para muchos 
autores, diferenciar lo económico y lo simbólico es fundamentalmente un recurso analítico que permite por una parte comprender la totalidad social pero principalmente explicar con fundamento procesos sociales de amplio rango.

Bórmida cae en el mismo error (que tanto reprueba) del marxismo mecanicista (y que él atribuye a la totalidad del marxismo) de considerar como compartimentos estancos los fenómenos simbólicos y los económicos.

Su crítica no es novedosa; Godelier señala que frente a la centralidad de lo material y económico para explicar la naturaleza, la lógica interna, las condiciones de surgimiento y evolución de las sociedades se han planteado distintos argumentos que enfatizan la primacía de otras instituciones y funciones ${ }^{12}$.

\footnotetext{
"Al primado de la economía en todas las sociedades, que proponen los marxistas, oponen los no marxistas el del parentesco entre los aborígenes australianos o los nuer (Radcliffe Brown) o el de la religión (L. Doumond) en los sistemas de castas de la India, o bien el de la política en la Atenas del siglo V A.C. (K. Polanyi, Ed. Will)" (Godelier, 1989:154-155).
}

M. Bórmida, al igual que otros autores opuestos a los planteos marxistas, señala la inexistencia de un orden jerárquico entre instituciones y funciones. No obstante, apunta fundamentalmente a la imposibilidad de reducir la realidad a cualquiera de las categorías e instituciones (y aún funciones) señaladas como la piedra de toque que permiten comprender la totalidad social. Esto no significa que haya abjurado de trabajar las relaciones entre lo material y lo ideacional.

Como hemos señalado, érgon y mito. Una hermenéutica de la cultura material de los
Ayoreo del Chaco Boreal ${ }^{13}$ es el trabajo en el cual M. Bórmida aborda más sistemáticamente la temática antedicha. En él se propone:

"(...) describir los artefactos de (...) los Ayoreo del Chaco Boreal; por rescatarlos en su condición de contenidos de conciencia; por conocerlos, no ya muertos, es decir, en su aspecto tipológico y tecnológico materiales (...) sino vivientes, viéndolos en cuanto focos en los que convergen y se concretan las estructuras de pensamiento y de la vida de esa cultura (...)"14 (2005:6). "Nos proponemos hacer que un artefacto Ayoreo se nos revele tal como lo ve, lo piensa, lo teme y lo utiliza un indígena de este grupo (...)" (Ibídem).

Es significativo que Bórmida reduce la materialidad a una dimensión morfológica, siendo la ergología casi sinónimo de cultura material, que a su vez es concebida como el estudio de los "utensilios", de las "cosas"15.

Las "cosas" no son producto exclusivo del trabajo del hombre sino resultante de ciertos contenidos de conciencia propios de los ayoreo. La relevancia de los nanibahái (entendidos estos como figuras que existieron en tiempos originarios, presentando características humanas) es central para la interpretación bormidiana del érgon. "Este personaje se metamorfosea en el primer ente (o prototipo) de una especie u otorga prototipo y permanece en una relación de potencia con los entes que se derivan de este prototipo o se vinculan con él" (Ídem: 38).

En la conciencia del ayoreo existiría (preconfigurada) la idea del prototipo de los artefactos, en el que estarían incluidos sus aspectos funcionales y morfológicos. Pero la morfología, de un modo u otro, es la resultante de la intención de un manibahái y en él encuentra su razón de ser y su sentido. El artefacto es resultado de la metamorfosis del nanibahái. En él no solo se 
patentiza la transformación del mismo, sino que se manifiesta la potencia del érgon. El horizonte mítico se proyecta sobre la sociedad a través de la materialidad del prototipo.

Entre lo humano y el ente primigenio (el prototipo donado) se constituye un campo ambiguo no solo atinente a cuestiones morfológicas sino también pragmáticas ${ }^{16}$.

"La forma del érgon es, en cierto modo, la forma del nanibahái que se metamorfoseó en él” (1976a:31).

"La forma del érgon ayoreo es a través de su prototipo, el producto de la actividad no ya del hombre sino de un nanibahái. El origen de la forma de un artefacto se halla, entonces (...) no en la iniciativa del hombre sino se funda en el horizonte mítico originario. La forma de érgon se independiza, entonces de su artífice humano y se percibe como algo dado en el prototipo de una vez y para siempre" (Op.cit.:37).

En definitiva, según el autor, para los ayoreo el érgon no es resultado en principio de la actividad humana sino que está configurado previamente.

“(...) lejos de considerar la idea que preside a la fabricación del érgon como el producto de la inventiva de un hombre, el Ayoreo traslada casi siempre su formulación originaria a la actividad de una teofanía; a ésta se remite la aparición del "prototipo" del érgon del que los hombres actuales no son sino fieles imitadores" (2005:18).

La presentación del érgon, es reducida a su dimensión morfológica, a una réplica de los contenidos de conciencia previos, y aplica como un reduccionismo (similar al tipo de operaciones que preocupaban al autor).

M. Bórmida advierte sobre el "riesgo" de concebir el érgon como "objeto muerto" frente a la posibilidad de interpretarlo, merced a su concepción teórico-metodológica, como una "idea viviente" (Op.cit.:6). Esto invita a dos consideraciones:

En primer lugar, señalar el "lamento romántico" de que "sean guardados en una vitrina" (Ibídem) evidencia la imposibilidad de pensarlos como resultado de un proceso histórico que los "confinó" y redujo a "objetos de museo".

En segundo lugar, muestra las limitaciones (¿o desinterés?) por reconocer y analizar a estos objetos como resultado de determinadas relaciones sociales, económicas y políticas.

El intento de del autor al abordar "lo material" está orientado para refutar lo que él entiende por pensamiento positivista y aquello que en filosofía se concibe como materialismo. La "riqueza cultural" de un artefacto (Ibídem) estriba en tanto trasciende su materialidad, uso y función. En definitiva, en tanto es resultado de un "contenido de conciencia" carecen de importancia los aspectos históricos y las relaciones sociales que definen su producción, circulación y consumo. En línea con lo señalado nada nos dice de los mecanismos de apropiación ni de las condiciones de alienación de los pueblos originarios, "sujetos" de sus investigaciones.

La materialidad concebida por Bórmida, escinde lo material y lo simbólico. Su propuesta lleva a la renuncia expresa de realizar cualquier diseño relacional. La imposibilidad de plantear las vinculaciones entre la naturaleza, el trabajo (siempre social), la organización social y los fenómenos ideacionales, hace que su explicación de la "cultura material" (usando sus términos), tenga en la práctica una explicación monocausal. En sus términos, el érgon es fruto de un "contenido de conciencia" y dicho esto, cualquier aspecto social, económico, histórico etc. carece de importancia para explicar su existencia. 
La relación dialéctica entre lo ideacional y lo material tiene pues, en la perspectiva bormidiana, un vínculo particular. No es lo ideacional, en sentido lato (en la medida que los aspectos ideológicos, los criterios clasificatorios y otras construcciones simbólicas están fuera de toda consideración), sino específicamente lo que el autor entiende por "contenidos de conciencia" y "horizonte mítico", los que configuran, ordenan $\mathrm{y}$ validan cualquier aspecto de la totalidad.

\section{Palabras finales}

Para culminar este trabajo cabe asumir que la centralidad que le cupo a M. Bórmida nos lleva a repensar la formación recibida por todos los estudiantes (y nos incluimos) que cursamos la carrera de antropología en aquellos oscuros años. No solo para plantear las carencias que fue necesario salvar, sino fundamentalmente para dimensionar como incidió en el posterior desarrollo disciplinar. En definitiva, como operó este investigador, que fuertemente obliterado (por algunos de manera inconsciente, por otros dado el carácter vergonzante, teniendo en cuenta su desarrollo curricular inicial) fijó fuertes constricciones para el progreso de la antropología argentina.

En este trabajo procuramos primeramente plantear que más allá del oscurecimiento de la temática económica en las investigaciones de campo y de la prédica recurrente para invalidarla como categoría de análisis en contextos culturales diversos, se encuentra presente en la obra de Bórmida una concepción de lo económico que contribuyó a delinear temas y líneas de investigación que soslayaron variables e indicadores centrales para el análisis sociocultural. De igual manera, la concepción de "historia" (y las comillas apuntan a destacar lo particular de la interpretación bormidiana) tuvo implicaciones teóricas muy fuertes. Quizás sea en este punto donde se manifiestan de manera más cristalina las posiciones políticas e ideológicas de nuestro autor. Resulta sumamente ilustrativo observar el lugar que tendrían asignado, según su propuesta, los pueblos originarios en el proceso histórico. Al respecto, Ratier señala, refiriéndose no solo a Bórmida sino también a sus seguidores, que el (supuesto) "(...) respeto retórico al "otro cultural" chocaba con el trasfondo ideológico fascistizante de estos investigadores, que trataban al indígena como mera fuente de datos históricos, sin la menor preocupación por su realidad presente" (Ratier, 2010:26). "El indio solo sirve como testimonio histórico o para justificar una sociedad de beneficencia (...)", decía Marcelo Bórmida" (comunicación personal).

De acuerdo a la concepción bormidiana, las poblaciones indígenas cumplen la función de ilustrar el devenir histórico de "la razón", que es a su entender, la historia de la civilización. A su vez, en tanto eran reconocidas como un fenómeno marginal, se las construye como un objeto asistencial y residual, a las cuales es conveniente preservar. "La muerte de cada una de estas culturas es la muerte de una parte del espíritu humano (...)" [El etnógrafo tendría como responsabilidad central] "(...) salvar para la posteridad un conocimiento que permita incorporar para siempre al saber humanista las experiencias de las culturas etnográficas (...)" (1976a:7). Esta concepción postula un humanismo abstracto que considera, como ya señaláramos, a un indio sin clase y sin historia.

Para Bórmida la etnología se diferenciaba de la filosofía, pero debía mantener contigüidades (y aún yuxtaposiciones) con esta disciplina. 
La particular apropiación de la fenomenología husserliana en procura de reducir "juicios e interpretaciones de carácter histórico" (Bórmida, 1976b:62) constituye una clara operación metodológica cuyo resultado es la simple enunciación de "(...) un inventario de estructuras irracionales de sentido propias del extrañamiento (...)" (Op.cit.:94). Práctica que no es neutra en la medida que excluye cualquier comprensión racional del fenómeno etnográfico.

"El extrañamiento de las culturas a nivel etnográfico se concreta fundamentalmente en la imposibilidad de racionalizar, es decir, dominar con el intelecto, a una ingente cantidad de manifestaciones tales como se dan en la realidad vivida. La esfera de lo irracional, algo más limitada en la cultura occidental parece estar omnipresente" (Ídem: 19).

En el último apartado de este texto abordamos el relacionamiento entre la dimensión simbólica y la material. El autor hace múltiples referencias a esta cuestión en sus trabajos, sin embargo, nos hemos centrado en su análisis de la ergología de los ayoreo ${ }^{17}$ dado que el mismo constituye una versión iconográfica del pensamiento del autor. En él, Bórmida plantea que los ayoreo cuando producen sus utensilios se limitan a replicar los prototipos previamente donados por las deidades (nanibahai) en los "tiempos míticos".

Sobre esta interpretación bormidiana de la proyección mítica en las formas y los contenidos de la materialidad de los ayoreo, Tiscornia \& Gorlier señalaban en los inicios del período democrático:

\footnotetext{
"Parecería así que cuando los primitivos han debido resolver las cuestiones prácticas de la vida -los problemas de la subsistencia y de relaciones- sólo han estado preocupados por un interés casi académico por la metafísica, y una vez resuelta, de una vez y para
}

siempre, la explicación del mundo, justificación de sus acciones, debieron pagar el precio de no ser más hombres: no tienen posibilidad de duda, de creación de reflexión, quedando condenados a la repetición de los actos primigenios que dan razón de esa peculiar existencia (...)" (Tiscornia \& Gorlier, 1984:33).

Acertadamente estos autores advierten la circularidad de la construcción bormidiana que impide concebir cualquier aspecto creativo propio de la actividad humana. No solo los aspectos materiales se presentan cristalizados (ni que hablar del desarrollo de las fuerzas productivas) sino que la dimensión ideacional también es presentada estáticamente. La conciencia mítica es una y se replica ad infinitum. La dinámica social, los procesos históricos, las modificaciones en las condiciones de existencia, la coexistencia con otros sistemas de representaciones no alcanzan a modificarla ni a cambiar los contenidos de conciencia de los "pueblos etnográficos". El cambio solo es interpretado como pérdida y degradación.

Así las cosas, hay en Bórmida una marcada consistencia en la forma de concebir las cuestiones relacionales entre los aspectos materiales, las representaciones simbólicas y la historia. Consistencia que se pudo superar solamente a partir de un radical cambio epistemológico. Para que este aconteciera, para que otros formatos teórico-metodológicos pudieran implementarse fue necesario el drástico viraje político que significó la recuperación de la democracia, lo que marca (y no por obvio queremos dejar de mencionarlo) cómo la figura de M. Bórmida y su influencia sobre la antropología argentina fue potenciada por el autoritarismo imperante en nuestro país entre 1955 y 1983.- 


\section{Notas}

${ }^{1}$ Este artículo forma parte de una investigación en curso.

${ }^{2}$ Partido político, surgido de la división de la Unión Cívica Radical en 1957.

${ }^{3}$ En línea con esto las restricciones a la pesca que regulan la actividad económica de los wichi son entendidas como manifestaciones de la conciencia mítica. lláh, dueño del río y del pescado retiraría los animales si se pescara más de los animales necesarios para alimentarse. Se descartan explicaciones ecologistas sobre la regulación de los recursos, así como también las prescripciones elaboradas a partir de un intenso trabajo clasificatorio.

${ }^{4}$ Dentro de las reducciones racionalistas que impiden la captación del hecho etnográfico, el autor incluye críticas a la antropología clásica. Tylor y Frazer son cuestionados en la medida que su abordaje racionalista les impide comprender los sentidos profundos de la religión y la magia. En otros trabajos la crítica se extiende sobre Bacon, Descartes, Lamarck y Darwin (Bórmida, 1958-1959b:70-78) por su intento de "crear una historia natural".

${ }^{5}$ Muchos años antes del desarrollo de la fenomenología bormidiana, Boas escribía: "La teoría del determinismo económico no es más adecuada que la del determinismo geográfico. No hay razón para considerar las demás fases de la cultura como una superestructura levantada sobre una base económica" (1964:197).

${ }^{6}$ Bórmida se basa en dos trabajos de Godelier (1966) Sobre el Modo de producción asiática (1966) y Racionalidad e irracionalidad en la economía (1967).

${ }^{7}$ Afirmamos esto pese a los intentos de Bórmida por despegarse del relativismo. Su planteo consiste en procurar la reducción de lo subjetivo en el proceso de conocimiento (reducción fenomenológica). Esta reducción nunca es completa, sino que consiste en una actitud cognoscitiva que procura disminuir (en lo posible eliminar) el saber adquirido por el etnógrafo que se proyecta en sus juicios y categorizaciones (1976b:68).

${ }^{8} \mathrm{D}$. Kahneman es el máximo referente de la economía conductista. Premio Nobel en el año 2002 por sus trabajos de investigación (realizados conjuntamente con A. Tversky), procuraron establecer fuertes nexos entre la economía y la psicología. Su interés consistía en explicar los mecanismos que operan en la toma de decisiones. Los estudios de ambos representan un desafío para la teoría económica clásica, según la cual los individuos siempre actúan racionalmente.

${ }^{9}$ Cuando analiza las influencias de las corrientes materialistas en el pensamiento etnológico cita como ejemplo a Vogts cuando asimila que el cerebro produce pensamientos como el hígado, bilis y los riñones, orina (1958-1959b: 63-64).

${ }^{10}$ Bórmida considera este término como un "Neologismo introducido por el indoeuropeista V. Pisani por analogía con el de "isoglosa" de la Lingüística" (1956:14). El registro y la comparación de los patrimonios culturales permiten la constitución de grupos culturales regionales. La configuración de bienes comunes posibilita la enunciación de un "sistema orgánico de isoidas" (1956:14).
11 ¿No es éste quizá un caso (no tan extraño por otra parte) en que el etnólogo se deja engañar por el indígena? Y no por el indígena en general, que no existe, sino por un grupo indígena (...). En este caso en lugar de aplicar hasta el final sus principios, Mauss renuncia a favor de una teoría neozelandesa que tiene gran valor como documento etnográfico, pero que no deja de ser una teoría (...). No hay motivo para que, porque unos sabios maoris se hayan planteado los primeros unos problemas y los hayan resuelto de una forma atractiva, pero poco convincente, tengamos que aceptar su interpretación" (Lévi-Strauss, 1979:33).

12 En su trabajo La parte ideal de lo material, Godelier señala que toda relación social "(...) incluye una parte ideal, una parte de pensamiento, de representaciones; estas representaciones no son únicamente la forma en que reviste esa relación para la conciencia, sino que forman parte de su contenido (...) lejos de ser una instancia separada de las relaciones sociales, de ser su apariencia, su reflejo deformado-deformante en la conciencia social, forman parte de las relaciones sociales desde que comienzan a formarse y son una de las condiciones para su formación. Pero si hay algo de ideal en todo lo real social, no todo es ideal en ese real" (1989:157).

${ }^{13}$ Hemos utilizado para el trabajo "Ergon y mito. Una hermenéutica de la cultura material de los Ayoreo del Chaco Boreal" las publicaciones: Archivos. Departamento de Antropología Cultural (2005) y Scripta Ethnologica. Archivo para una fenomenología de la cultura (1976a).

${ }^{14}$ No queremos dejar de señalar la concepción de Bórmida sobre el grupo que lo iba a recibir para que realizara su trabajo de campo. En la introducción del trabajo citado el autor nos advierte que "(...) los Ayoreo constituyen un grupo muy agresivo y que su progresivo contacto pacífico con la Civilización Occidental se remonta apenas a unos veinte años" (2005:8).

${ }^{15} \mathrm{M}$. Bórmida señala que "En la categorización tradicional de la cultura se entiende por Ergología el estudio de los productos materiales de la actividad fabril, destinados a satisfacer ciertas necesidades del hombre. Así definido el concepto de ergología apenas se diferencia del de Tecnología" (2005:17).

${ }^{16} \mathrm{~A}$ lo largo del trabajo de referencia, la eficacia mágica aparece soterrada, aunque nunca es reconocida explícitamente por Bórmida. "Cuando el Arco era persona había dos de ellos: Orohoí era el Arco que falla y Asnakai el Arco que acierta (...)" (Bórmida1976a:32). “(...) el Ayoreo considera que pueden interferir en su actividad fabril factores que no dependen de su intencionalidad. Estos factores se remiten al horizonte mítico o a una revelación; no tomarlos en cuenta implica no sólo el fracaso de la obra sino también un peligro para la integridad o para la vida misma de quien la realiza (...)" (2005:17).

${ }^{17}$ Nos referimos a su trabajo "Ergon y mito. Una hermenéutica de la cultura material de los Ayoreo del Chaco Boreal" publicado en sucesivos números de Scripta Ethnologica. 


\section{Referencias Bibliográficas}

Boas, F. (1964). Cuestiones fundamentales de Antropología Cultural. Buenos Aires: Hachette.

Bórmida, M. (1956). "Cultura y ciclos culturales. Ensayo de Etnología Teorética”. Runa. Archivo para las ciencias del hombre. Vol. VII, № 1.

(1958-1959a) "El estudio de los Barbaros desde la antigüedad hasta mediados del siglo XIX. Bosquejo para una historia del pensamiento etnológico". Anales de Arqueología y Etnología. Tomos XIV-XV, Mendoza: Universidad nacional de Cuyo.

(1958-1959b) "Bosquejo para una historia general del pensamiento etnológico II Parte. La antropología del materialismo". RUNA. Archivo para las ciencias del hombre. Vol. IX, Partes 1 y 2. (1969-1970) "Mito y cultura. Bases para una ciencia de la conciencia mítica y una etnología tautegórica". RUNA. Archivo para las ciencias del hombre. Vol. XII, Partes 1 y 2.

(1976a) "Érgon y mito Una hermenéutica de la cultura material de los Ayoreo del Chaco Boreal". Scripta Ethnologica, 4/1: $29-44$.

Cervantes.

(1976b). Etnología y Fenomenología. Buenos Aires:

(2005) "Érgon y mito. Una hermenéutica de la cultura material de los Ayoreo del Chaco Boreal". Archivos. Departamento de Antropología Cultural CIAFIC Ediciones.

Douglas, M. \& Isherwood, B. (1990). El mundo de los bienes. Hacia una antropología del consumo. México: Grijalbo.
Godelier, M. (1966). "La noción de "Modo de producción asiático" y los esquemas marxistas de evolución de las sociedades en $\mathrm{C}$. Marx". Argentina: Quintaria.

(1967). Racionalidad e irracionalidad en la economía. México: Siglo XXI.

(1989) Lo ideal y lo material. Pensamiento, economías, sociedades. Madrid: Tauros Humanidades.

Gordillo, G. (1996). "Hermenéutica de la ilusión: La etnología Fenomenológica de Marcelo Bórmida y su construcción de los indígenas del Gran Chaco". Cuadernos de Antropología Social, № 9. FFyL. UBA.

Herrán, C. (1990). "Antropología Social en la Argentina. Apuntes y perspectivas". Cuadernos de Antropología Social Vol. 2. № 2 FFyL. UBA.

Lévi-Strauss, C. (1979). "Introducción a la obra de Marcel Mauss". En Mauss, M. Sociología y Antropología. Madrid: Tecnos.

Ratier, H. (2010). "La antropología social argentina: su desarrollo". Publicar. Año VIII, № IX - junio.

Tversky, A. \& Kahneman, D. (1981). "The Framing of Decisions and the Psychology of Choice". Science, New Series, Vol. 211, № 4481, pp. 453-458.

Tiscornia, S. \& Gorlier, J. (1984). "Hermenéutica y fenomenología: exposición crítica del método fenomenológico de M. Bórmida”. Etnia № 31.

Veblen, T. (1951). Teoría de la clase ociosa. México: FCE. 